\title{
AVALIAÇÃO DA IMPLANTAÇÃO E DESEMPENHO DO PLANO DE GERENCIAMENTO DE RESÍDUOS SÓLIDOS - COMPARATIVO ENTRE OBRAS RESIDENCIAIS PLURIFAMILIARES
}

\section{IMPLEMENTATION AND PERFORMANCE EVALUATION OF SOLID WASTE MANAGEMENT PLAN - COMPARISON OF MULTI-FAMILY CONSTRUCTION WORKS}

\section{Sergio Arnosti Jr*; Ana Cláudia Trinca}

Escola de Engenharia de Piracicaba, Piracicaba, SP. Av. Monsenhor Martinho Salgot $n^{\circ} 560$ - Vila Areão. CEP: 13414-040 - Piracicaba/SP

*Autor para correspondência: e-mail sergioarnosti@gmail.com

\begin{abstract}
RESUMO
Neste estudo elaborou-se análise comparativa, buscando apresentar de forma qualitativa e quantitativa as principais vantagens da implantação de um plano de gerenciamento de resíduos sólidos (PGRS). Para tanto foram comparadas duas obras plurifamiliares residenciais de uma mesma construtora, sendo uma com o PGRS implantado e a outra não. Os parâmetros comparados foram: o volume de resíduos gerados, o custo para destinação final adequada dos resíduos (ambos comparados por blocos (com 16 unidades habitacionais cada) e por $\mathrm{m}^{2}$ construído), assim como o tempo para implantação do PGRS em relação ao cronograma da obra. Constatou-se que a implantação do PGRS gerou uma economia financeira de cerca de $60 \%$ nos custos de destinação final de resíduos, bem como a redução de aproximadamente $67 \%$ na geração de resíduos para a obra com PGRS, tendo requerido somente $2 \%$ do tempo de execução da obra.
\end{abstract}

Palavras-chave: Resíduo sólido. Construção Civil. Gerenciamento de obras.

\begin{abstract}
This study was elaborated seeking to present a comparative analysis of the main advantages of implementing a solid waste management plan (SWMP) in a qualitative and quantitative way. Therefore, we compared two residential multi-family construction works of the same construction company, one with the implanted SWMP and the other not. The parameters compared were: the volume of waste generated, the cost of proper disposal of waste (both compared by blocks (with 16 housing units each) and built $\mathrm{m}^{2}$ ), as well as time for implementation of the SWMP of schedule of work. It was found that the implementation of the SWMP generated financial savings of about $60 \%$ in the final costs of waste disposal, and the reduction of approximately $67 \%$ in waste generation, to work with SWMP required only $2 \%$ of the work runtime.
\end{abstract}

Keyword: Solid waste. Construction. Works management. 


\section{INTRODUÇÃO}

A engenharia civil é agente de transformação de ambiente natural em ambiente construído. Durante muito tempo, estas transformações foram realizadas de forma semelhante a um modelo de produção linear, seguindo etapas como planejamento, projeto, produção e uso, resultando em rejeitos provenientes do consumo dos recursos naturais próximos.

Embora a preservação ambiental tenha sido por muito tempo vista como uma ação antidesenvolvimentista, nos dias atuais se tornou uma preocupação e necessidade mundial, devido ao crescimento populacional e aos desenvolvimentos econômico e social, precursores da maioria dos impactos negativos observados. Dessa forma, áreas antes preservadas passam hoje a ser transformadas, havendo necessidade de se implantar metodologias eficazes para o acompanhamento dos resíduos gerados, de modo a minimizar o impacto predatório sobre os recursos naturais, garantindo sua disponibilidade para as gerações futuras, ou seja, utilizando-os de forma sustentável.

Em vista destes fatos, o setor da construção civil tem a obrigação de tentar mudar essa realidade, seguindo diretrizes cada vez mais rígidas e desenvolvendo projetos para resolver os transtornos causados pela disposição de resíduos em locais irregulares. Busca-se cada vez mais a construção sustentável, principalmente por se tratar de um setor de alta influência socioeconômica, que é responsável por uma grande geração de empregos, renda, pela viabilização de moradias, infraestrutura e estradas.

Atualmente, cada empresa desenvolve sua metodologia própria quanto à destinação final de seus resíduos, devendo tal procedimento ser exposto de forma clara a todos os funcionários envolvidos, para que estes possam colaborar com os projetos. Segundo Salgosa e Del Bel (2012), o Brasil vem apresentando nos últimos anos uma grande preocupação e conscientização em relação a problemas ambientais, embora ainda apresente um significativo atraso, se comparado com países desenvolvidos. Para auxiliar a resolver tais problemas ambientais, novas diretrizes foram estabelecidas por meio, principalmente, do Conselho Nacional de Meio Ambiente (CONAMA) por ordem da sua Resolução $n^{\circ}$ 307, de 5 de julho de 2002 (BRASIL, 2002), inclusive com suas atualizações através da Resolução n 431, de 25 de maio de 2011 (BRASIL, 2011) e da Resolução $\mathrm{n}^{\circ} 448$, de 19 de janeiro de 2012 (BRASIL, 2012).

Em paralelo as resoluções tem-se a Política Nacional de Resíduos Sólidos - Lei n 12.305 , de 2 de agosto de 2010 (BRASIL, 2010), definindo bases sólidas para planejar e programar uma gestão apropriada para tais resíduos, podendo-se destacar diretrizes como redução de desperdícios e volumes de resíduos gerados, correta separação dos resíduos em classes e tipos, reutilização de materiais que não precisem de transformações para tal e reciclagem dos resíduos, transformando-os novamente em matéria-prima.

Um dos problemas que as construtoras enfrentam se refere à insegurança sobre a viabilidade da iniciativa de se implantar um plano de gerenciamento de resíduos, principalmente pela existência de poucas experiências implantadas nos canteiros. Este estudo teve por objetivo comparar, de forma qualitativa e quantitativa, duas obras plurifamiliares residenciais, sendo uma delas com o plano de gerenciamento de resíduos implantado e a outra não. Para tanto, foram escolhidas obras realizadas por uma mesma construtora e os parâmetros considerados foram: os volumes de resíduos gerados (mensalmente e durante o período total de execução da obra), os custos da destinação final dos resíduos gerados, assim como o tempo para implantação do plano de gerenciamento de resíduos em relação ao tempo de execução da obra; sendo tais valores apresentados por torre com 16 unidades habitacionais e por $\mathrm{m}^{2}$ construídos. 


\section{MATERIAL E MÉTODOS}

\subsection{Escolha e Caracterização das Obras Plurifamiliares Residenciais}

Foram analisados dois canteiros de obras residenciais plurifamiliares nas cidades de Uberlândia e Uberaba, no estado de Minas Gerais, ambos participantes do programa "Minha Casa Minha Vida". Considerou-se também a localização próxima entre as obras, além do que ambas possuem o mesmo padrão habitacional, seguindo as diretrizes e padrões estabelecidos pelo SiAC (2012), verificados em auditorias realizadas periodicamente.

Os dados referentes a cada empreendimento foram disponibilizados pelo departamento de controle da construtora, com sede em Belo Horizonte (MG), ganhadora da certificação de nível A do Programa Brasileiro de Qualidade e Produtividade na Habitação, sendo uma das primeiras construtoras a atingir este nível máximo de qualificação. Os valores dos parâmetros analisados representam todo o período de execução das obras.

A Obra A, localizada em Uberaba, foi escolhida por ter sido executada sem a implantação do plano de gerenciamento de resíduos sólidos (PGRS), sendo iniciada em outubro de 2011 e finalizada em dezembro de 2012. Este empreendimento conta com 512 apartamentos de 44,01 $\mathrm{m}^{2}$, distribuídos em 32 torres com 16 unidades habitacionais cada, resultando em $22.533,12 \mathrm{~m}^{2}$ de área construída.

A Obra B, em Uberlândia, foi escolhida por ter sido executada com a implantação do PGRS, sendo seu início em fevereiro de 2011 e término em setembro de 2012. O empreendimento conta com 1.232 apartamentos de 44,26 $\mathrm{m}^{2}$, agrupados em 77torres com 16 unidades habitacionais cada, perfazendo uma área total de construção de $54.529,12 \mathrm{~m}^{2}$.

\subsection{Parâmetros Qualitativos e Quantitativos Analisados}

Os parâmetros qualitativos e quantitativos analisados na comparação dos empreendimentos envolvidos neste estudo foram selecionados por serem primordiais durante a execução de obras do tipo e porte em questão. De forma qualitativa, foram considerados parâmetros como organização do canteiro de obras, melhores condições de trabalho, segurança dos funcionários envolvidos na produção e qualidade dos serviços executados. Quanto aos parâmetros quantitativos, foram considerados dados totais por empreendimento, dados individualizados por tarefas e por $\mathrm{m}^{2}$ construído, tempo utilizado para a implantação do plano e os respectivos custos envolvidos.

Para o estudo qualitativo, a análise dos resultados foi baseada em imagens disponibilizadas pela construtora. A partir das imagens compararam-se as situações reais apresentadas nos canteiros das Obras A e B, quanto à organização e aproveitamento do espaço disponível, analisando as implicações relacionadas à segurança e qualidade do trabalho executado.

O estudo quantitativo, através dos dados disponibilizados pela construtora, foi comparado quanto as áreas totais construídas, os volumes de resíduos gerados, os custos envolvidos para a disposição final dos resíduos, o tempo de execução da obra e o tempo utilizado para implantação do PGRS.

\section{RESULTADOS E DISCUSSÃO}

\subsection{Análise Qualitativa dos Empreendimentos}

Os resultados qualitativos referentes às Obras A e B, sem PGRS, são apresentados nas figuras 1 e 2, respectivamente. A comparação entre as figuras 1 e 2 evidencia que a implantação do PGRS é fundamental para a organização do canteiro de obras. A falta de segregação e de um local adequado para o armazenamento de resíduos, conforme mostrado nas figuras 1a, 1b e 1c, pode contribuir para o desperdício e para o aumento do risco de acidentes laborais. Estes fatos podem 
influenciar negativamente o ambiente de trabalho, reduzindo o comprometimento dos colaboradores com a segurança e com a questão ambiental envolvida. Conforme as figuras $2 \mathrm{a}, 2 \mathrm{~b}$ e $2 \mathrm{c}$, constata-se que a implantação do PGRS motiva uma série de ações que tornam o ambiente de trabalho mais organizado, seguro e que inclui os colaboradores no plano, incentivando a participação ativa de cada um, esclarecendo funções e ressaltando a importância dos aspectos econômicos, sociais e ambientais envolvidos e que dependem do sucesso do PGRS.

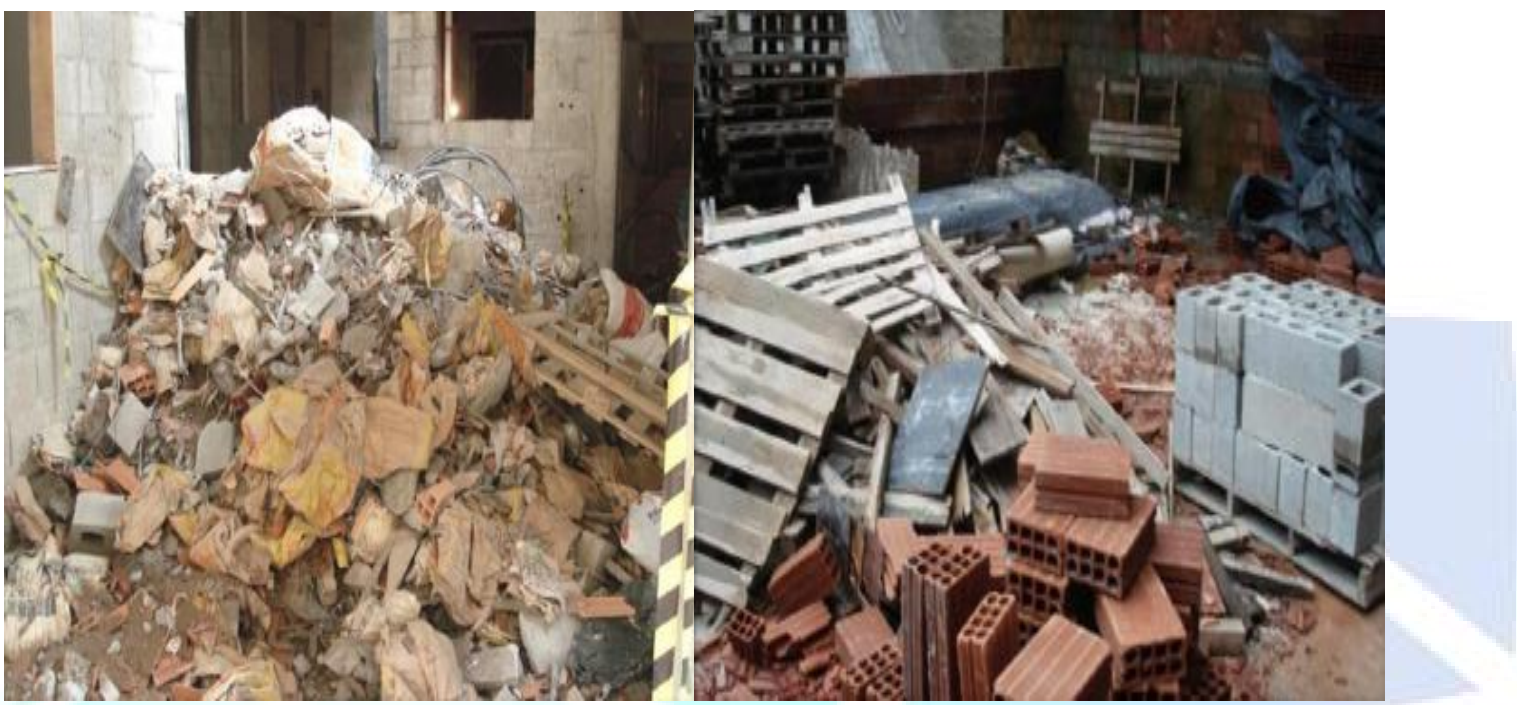

(a)

(b)
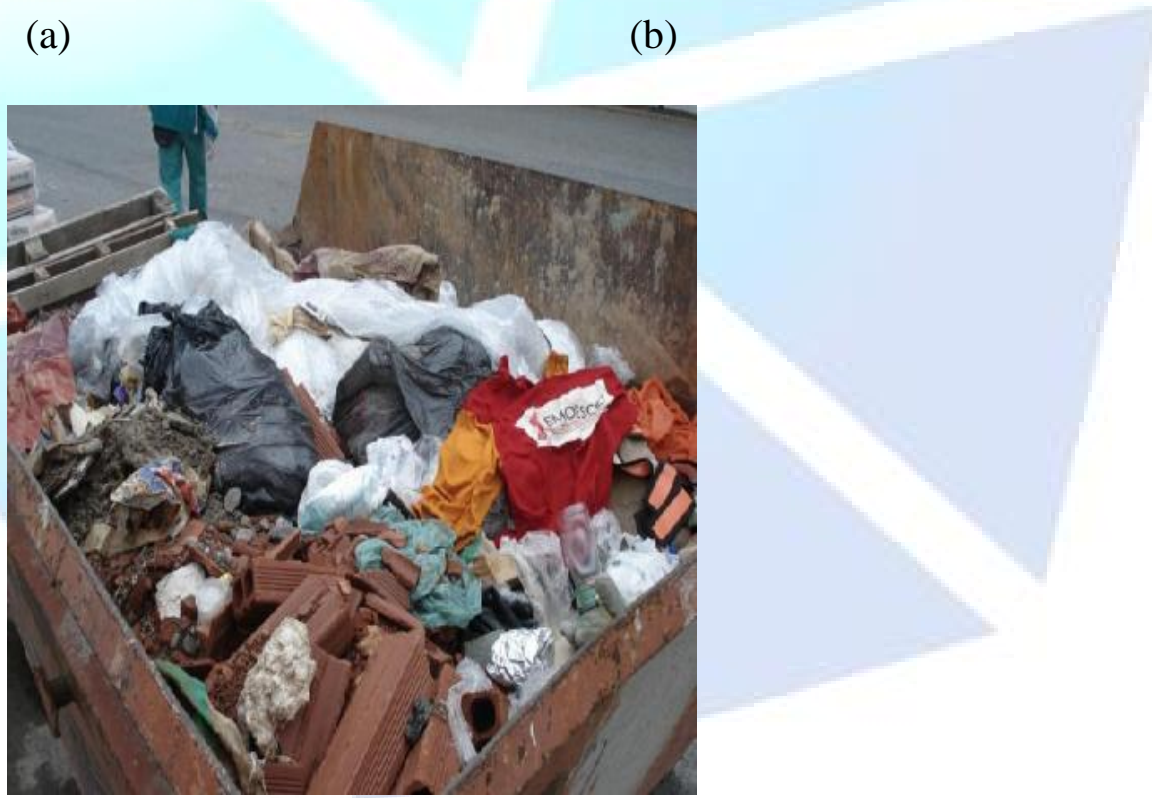

(c)

Figura 1. Imagens representativas dos resultados qualitativos da Obra A fornecidas pela construtora: (a) acúmulo de materiais no canteiro de obra, (b) armazenamento irregular de materiais novos com materiais já utilizados, (c) ausência de separação dos resíduos. Fonte: Construtora. 


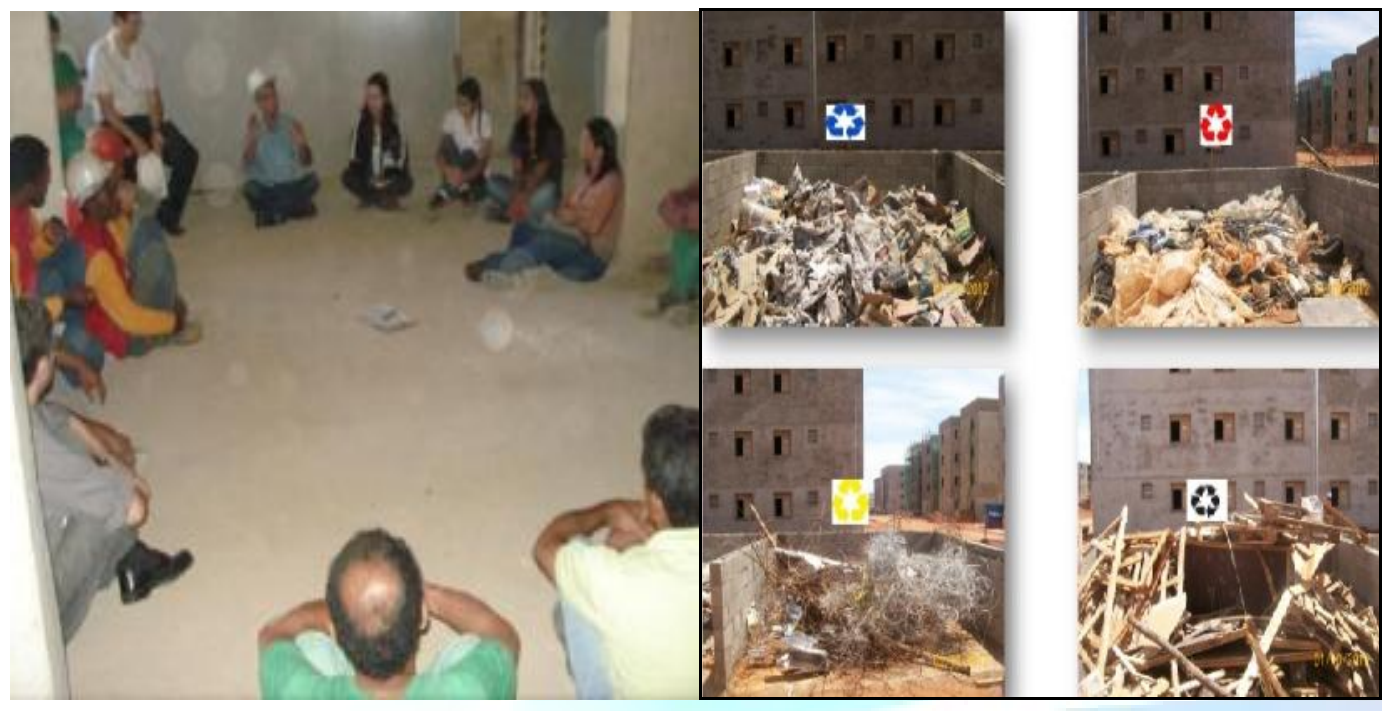

(a)

(b)

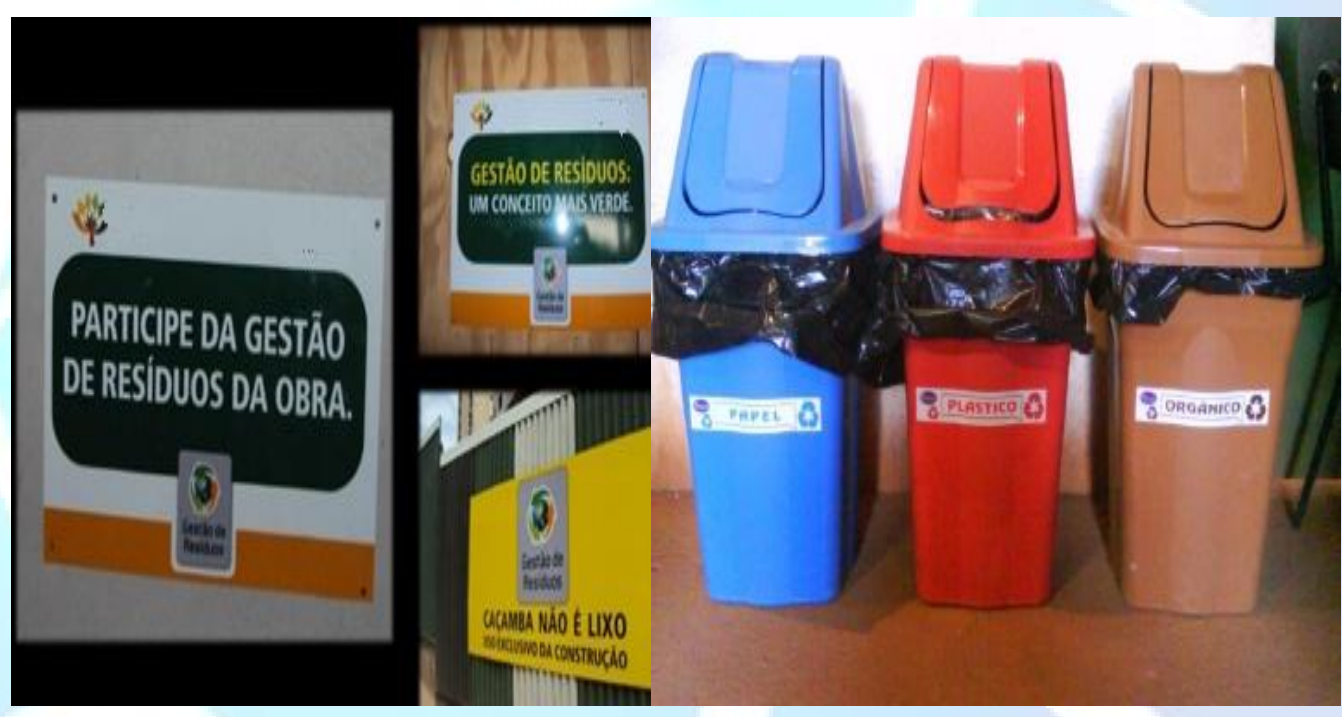

(c)

(d)

Figura 2. Imagens representativas dos resultados qualitativos da Obra B fornecidas pela construtora: (a) treinamento para capacitação dos funcionários, (b) utilização das baias para armazenamento e separação dos resíduos, (c) placas de conscientização espalhadas pelo canteiro, (d) instalação de lixeiras para coleta seletiva. Fonte: Construtora.

A partir dos resultados obtidos, observou-se que durante o desenvolvimento de uma obra, muitos fatores podem afetar a segurança e a qualidade do trabalho realizado. A falta de mão de obra especializada, as alterações de projeto, os materiais recebidos fora dos padrões de qualidade, o armazenamento irregular e a ausência de inspeções constantes estão entre os principais fatores contribuintes.

As figuras $2 \mathrm{a}, 2 \mathrm{~b}$ e $2 \mathrm{c}$ deixam evidente que o resultado encontrado condiz com a orientação de Pinto e González (2005), que diz que o planejamento deve incorporar também os canteiros de obra, identificando as equipes encarregadas para a remoção dos resíduos, a área em construção (distribuição do espaço, atividades desenvolvidas, materiais e equipamentos de transporte disponíveis), a verificação das possibilidades de reciclagem e reaproveitamento, assim como deve 
ser feito estudo sobre o monitoramento das ações, geralmente acompanhado por checklist e relatório periódico; além de considerar também, periodicamente, o desenvolvimento de treinamentos para as equipes, de forma a reforçar os conceitos e acompanhar as atualizações dos processos.

A partir das figuras $2 \mathrm{a}, 2 \mathrm{~b}$ e $2 \mathrm{c}$, constatou-se que na Obra $\mathrm{B}$ o gerenciamento de resíduos sólidos na construção civil traz benefícios ocupacionais, financeiros, sociais e ambientais convergindo para os princípios preconizados na Política Nacional de Resíduos Sólidos (BRASIL, 2010) e Resolução CONAMA nº 307 de 2002 (BRASIL, 2002).

\subsection{Análise Quantitativa dos Empreendimentos}

A tabela 1 apresenta os valores de custos de locação de caçambas (total e unitário), de quantidade de caçambas utilizadas (por bloco e por mês), volume total de resíduos gerados, tempo para implantação do PGRS e tempo aproximado de duração da execução da obra.

Estes valores foram calculados a partir dos dados relativos à Obra A obtidos junto ao departamento de controle da construtora.

Tabela 1 - Valores calculados para Obra A, base para análise comparativa entre obras. Fonte: O próprio autor.

\begin{tabular}{|c|c|}
\hline Locação de caçambas & $\mathbf{R \$ 9 7 . 1 2 0 , 0 0}$ \\
\hline Valor unitário das caçambas & $\mathbf{R \$ 1 7 6 , 6 7}$ \\
\hline $\begin{array}{c}\text { Quantidade de caçambas utilizadas para execução de } 1 \\
\text { bloco (16 unidades habitacionais) durante 14 meses }\end{array}$ & $\mathbf{5 5 0}$ \\
\hline Quantidade média de caçambas utilizadas por mês & $\mathbf{3 9}$ \\
\hline Volume mensal de resíduos ( $\left.\mathrm{m}^{3}\right)$ & $\mathbf{1 9 5}$ \\
\hline $\begin{array}{c}\text { Tempo utilizado para implantação de um plano de } \\
\text { gerenciamento de resíduos (dias) }\end{array}$ & N.A. \\
\hline Duração aproximada da execução da obra (dias) & $\mathbf{4 2 7}$ \\
\hline N.A = Não se Aplica
\end{tabular}

N.A. = Não se Aplica.

A tabela 2 apresenta os valores de custos de locação de caçamba (total e unitário), volume por tipo e destinação dos resíduos gerados, custos por tipo e destinação dos resíduos gerados (unitários e por mês).

Tabela 2 - Valores calculados para Obra B, base para a análise comparativa entre as obras. Fonte: O próprio autor.

\begin{tabular}{|c|c|c|c|c|c|c|c|c|}
\hline $\begin{array}{l}\text { Principais } \\
\text { Resíduos }\end{array}$ & $\begin{array}{c}\text { Volum } \\
\text { es Reais } \\
(19 \\
\text { meses }) \\
\left(\mathbf{m}^{3}\right)\end{array}$ & $\begin{array}{c}\text { Volumes } \\
\text { Reais Mensais } \\
\qquad\left(\mathbf{m}^{3}\right)\end{array}$ & $\begin{array}{l}\text { Destinação } \\
\text { Final }\end{array}$ & $\begin{array}{c}\text { Valores } \\
\text { unitários } \\
\text { gastos com a } \\
\text { destinação } \\
\text { final (por } \\
\text { caçamba) } \\
\end{array}$ & $\begin{array}{l}\text { Valores } \\
\text { recebidos } \\
\text { com a } \\
\text { destinação } \\
\text { final }\end{array}$ & Coleta & $\begin{array}{c}\text { Valor Gasto } \\
\text { Mensal }\end{array}$ & $\begin{array}{c}\text { Valor Gasto } \\
\text { Total (19 } \\
\text { meses) }\end{array}$ \\
\hline Entulhos & 1140 & 60 & JB Entulhos & $\mathrm{R} \$ 176,67$ & $\mathbf{R} \$ \mathbf{0 , 0 0}$ & \begin{tabular}{|l|} 
Caçamba \\
de $5 \mathrm{~m}^{3}$ \\
\end{tabular} & $\mathrm{R} \$ 2.120,04$ & $\mathrm{R} \$ 40.280,76$ \\
\hline Madeira & 526,4 & 27,71 & $\begin{array}{l}\text { Instituição } \\
\text { Beneficente }\end{array}$ & $\mathbf{R} \$ \mathbf{0 , 0 0}$ & $\mathbf{R} \$ \mathbf{0 , 0 0}$ & \multirow{4}{*}{$\begin{array}{l}\text { Os } \\
\text { próprios } \\
\text { receptores } \\
\text { fazem a } \\
\text { coleta }\end{array}$} & $\mathrm{R} \$ 0,00$ & $\mathbf{R} \$ \mathbf{0 , 0 0}$ \\
\hline Gesso & 65 & 3,42 & $\begin{array}{c}\text { Instituições de } \\
\text { Reciclagem }\end{array}$ & $\mathbf{R} \$ \mathbf{0 , 0 0}$ & $\mathbf{R} \$ \mathbf{0 , 0 0}$ & & $\mathrm{R} \$ 0,00$ & $\mathbf{R} \$ \mathbf{0 , 0 0}$ \\
\hline Metal & 38,4 & 2,02 & Ferro Velho & $\mathbf{R} \$ \mathbf{0 , 0 0}$ & $\mathbf{R} \$ \mathbf{2 0 7 , 5 0}$ & & $\mathrm{R} \$ 0,00$ & $\mathbf{R} \$ \mathbf{0 , 0 0}$ \\
\hline Outros & 246,2 & 12,96 & $\begin{array}{c}\text { Instituições de } \\
\text { Reciclagem de } \\
\text { Papelão / } \\
\text { Papéis } \\
\end{array}$ & $\mathbf{R} \$ \mathbf{0 , 0 0}$ & $\mathbf{R} \$ \mathbf{0 , 0 0}$ & & $\mathrm{R} \$ 0,00$ & $\mathbf{R} \$ \mathbf{0 , 0 0}$ \\
\hline & & & & & & & Total: & $R \$ 40.073,26$ \\
\hline
\end{tabular}


Verifica-se a partir dos resultados mostrados na tabela 2, referentes à destinação final dos resíduos gerados na Obra $\mathrm{B}$, que parcerias com empresas, instituições filantrópicas ou organizações não governamentais (ONGs) são muito importantes para o sucesso do PGRS, uma vez que estes parceiros, na maioria das vezes, retiram o material da obra sem custo algum para o empreendimento. Há ainda casos de empresas receptoras de metais, que além de recolher o material da obra ainda pagam um determinado valor proporcional a quantidade de resíduo coletado.

Existem ainda projetos sociais municipais, como o "Brechó da Construção", em Belo Horizonte, que recebe doações de materiais de construtoras ou fornecedores, ainda que em poucas quantidades - geralmente sobras de obras - para comercializá-los por preços simbólicos, resolvendo problemas sociais de moradias e dando uma nova oportunidade de reutilizar algo que seria tratado como um rejeito (CUNHA JUNIOR, 2005). Observa-se, também, que tais parcerias contribuem ainda no aspecto social para a construtora, podendo inclusive se reverter em marketing positivo.

Para que houvesse a implantação do PGRS na Obra B foram necessários 14 dias de treinamentos com as equipes, sendo que o cronograma para execução da obra era composto por 580 dias. Os custos envolvidos na implantação do PGRS na Obra B estão apresentados na tabela 3.

Tabela 3 - Custos envolvidos para a implantação do plano de gerenciamento de resíduos sólidos no canteiro de obras. Fonte: O próprio autor.

\begin{tabular}{|c|c|}
\hline Execução e identificação das 4 baias & $\mathbf{R \$ 1 . 4 8 1 , 6 0}$ \\
\hline $\begin{array}{c}\text { Compra de lixeiras para coleta seletiva (para uso nas áreas de vivência } \\
\text { dos funcionários, sendo escritório, refeitório e vestiários) }\end{array}$ & $\mathbf{R \$ 9 2 0 , 0 0}$ \\
\hline $\begin{array}{c}\text { Contratação de empresa para desenvolvimento e acompanhamento do } \\
\text { plano de gerenciamento de resíduos da obra }\end{array}$ & $\mathbf{R} \mathbf{6 . 3 0 0 , 0 0}$ \\
\hline Total: & $\mathbf{R \$ ~ 8 . 7 0 1 , 6 0}$ \\
\hline
\end{tabular}

Com base nos valores obtidos e que constituem as tabelas de 1 a 3 foram calculados os valores por área construída, volume de resíduos sólidos gerados (totais, por torre e por $\mathrm{m}^{2}$ construído), custo da obra (totais, por torre e por $\mathrm{m}^{2}$ construído), gasto com disposição final dos resíduos gerados (totais, por torre e por $\mathrm{m}^{2}$ construído), tempo de implantação do PGRS, tempo de execução da obra, para cada obra considerada nesse estudo. Os resultados são apresentados na tabela 4 e na tabela 5 para a Obra A e Obra B, respectivamente.

Tabela 4 - Obra A - Valores dos parâmetros de comparação. Fonte: O próprio autor.

\begin{tabular}{|c|c|c|c|}
\hline Parâmetros & Valores Totais & $\begin{array}{c}\text { Valores por Bloco - com } 16 \\
\text { unidades habitacionais }\end{array}$ & $\begin{array}{l}\text { Valores por } \mathbf{m}^{2} \\
\text { construído }\end{array}$ \\
\hline Área Construída $\left(\mathrm{m}^{2}\right)$ & $22.533,12$ & 704,16 & - \\
\hline Volume de Resíduos $\left(\mathrm{m}^{3}\right)$ & $2.730,00$ & 85,31 & 0,12 \\
\hline Custo da Obra (em reais) & $\mathrm{R} \$ 26.554 .533,33$ & $829.829,17$ & $1.178,47$ \\
\hline $\begin{array}{l}\text { Valor gasto com a disposição final } \\
\text { dos resíduos sólidos (em reais) }\end{array}$ & $\mathrm{R} \$ 3.107 .840,00$ & $97.120,00$ & 137,92 \\
\hline $\begin{array}{l}\text { Tempo para implantação do } \\
\text { PGRS (em dias) }\end{array}$ & N.A. & - & - \\
\hline $\begin{array}{l}\text { Tempo de execução da obra (em } \\
\text { dias) }\end{array}$ & 427 & - & - \\
\hline
\end{tabular}

N.A. = Não se Aplica. 
Tabela 5 - Obra B - Valores dos parâmetros de comparação. Fonte: O próprio autor.

\begin{tabular}{|c|c|c|c|}
\hline Parâmetros & Valores Totais & $\begin{array}{l}\text { Valores por Bloco - com } \\
16 \text { unidades habitacionais }\end{array}$ & $\begin{array}{l}\text { Valores por } \mathbf{m}^{2} \\
\text { construído }\end{array}$ \\
\hline Área Construída $\left(\mathrm{m}^{2}\right)$ & $54.529,12$ & 708,16 & - \\
\hline Volume de Resíduos $\left(\mathrm{m}^{3}\right)$ & $2.016,00$ & 26,18 & 0,04 \\
\hline Custo da Obra (em reais) & $62.158 .985,04$ & $807.259,55$ & $1.139,92$ \\
\hline $\begin{array}{l}\text { Valor gasto com a disposição } \\
\text { final dos resíduos sólidos (em } \\
\text { reais) }\end{array}$ & $3.094 .342,62$ & $40.186,27$ & 56,75 \\
\hline $\begin{array}{l}\text { Tempo para implantação do } \\
\text { PGRS (em dias) }\end{array}$ & 14 & - & - \\
\hline $\begin{array}{c}\text { Tempo de execução da obra (em } \\
\text { dias) }\end{array}$ & 580 & - & - \\
\hline
\end{tabular}

Para o estudo comparativo os resultados estão apresentados nas figuras de 3 a 6 . A figura 3 corresponde à comparação entre os volumes de resíduos gerados nas Obras A e B, por bloco com 16 unidades construído. Na figura 4 é apresentado um comparativo entre os volumes de resíduos gerados nas Obras A e B, por $\mathrm{m}^{2}$ construído.

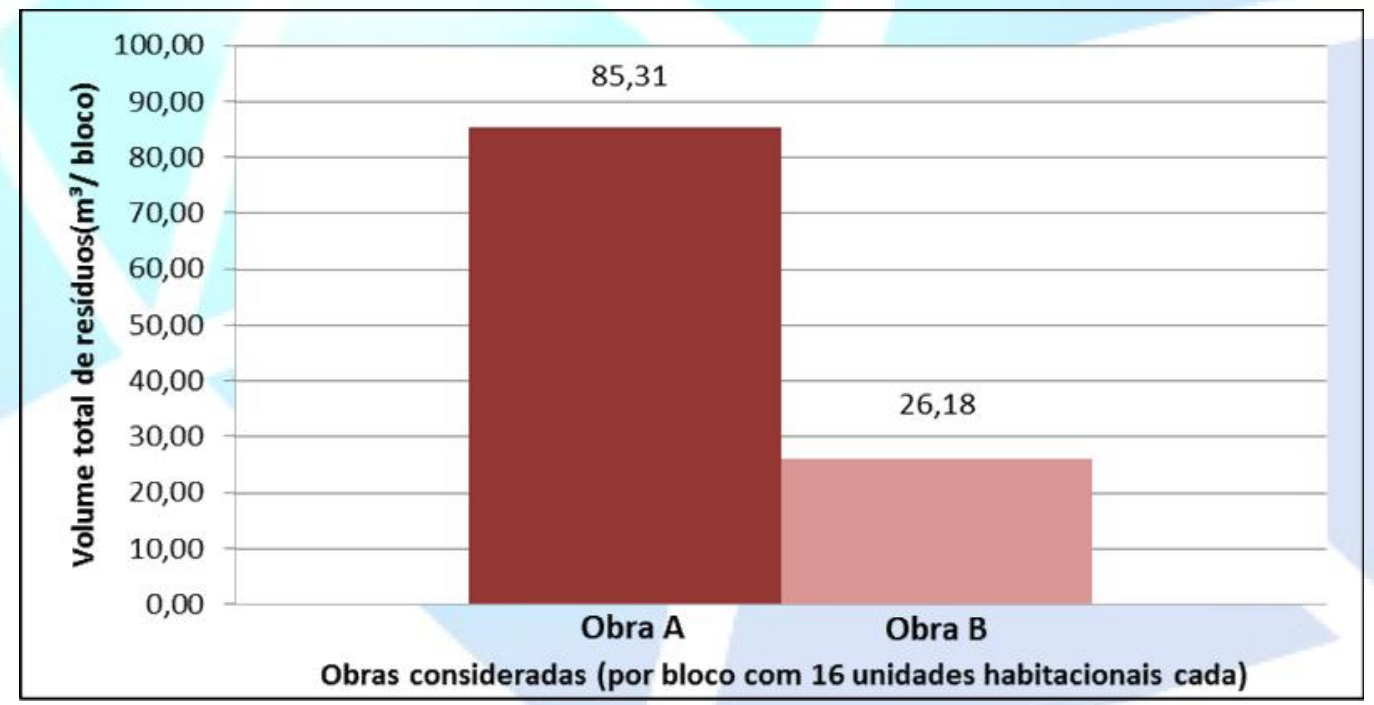

Figura 3. Comparativo de volumes de resíduos gerados $\left(\mathrm{m}^{3}\right)$, por bloco com 16 unidades habitacionais cada. Fonte: O próprio autor. 


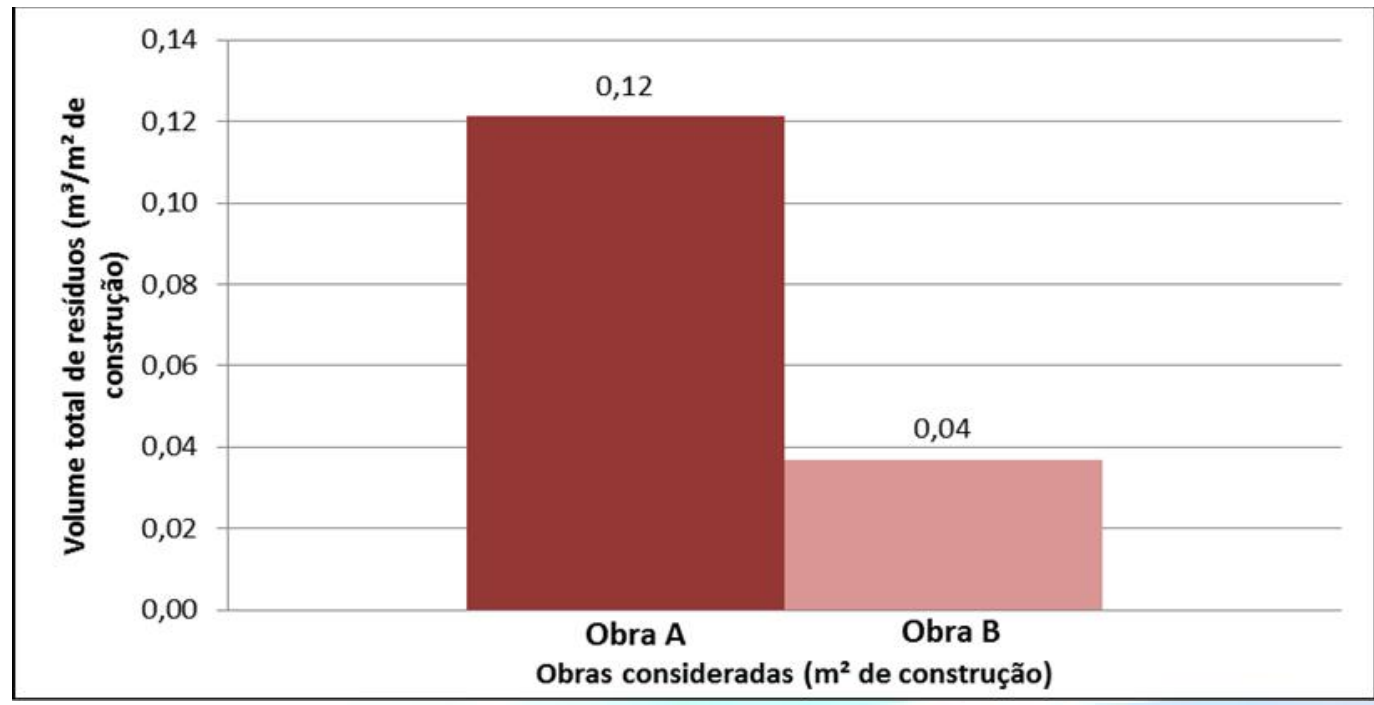

Figura 4. Comparativo entre os volumes de resíduos gerados $\left(\mathrm{m}^{3}\right)$, por $\mathrm{m}^{2}$ de construção. Fonte: O próprio autor.

A figura 5 contem resultados comparativos entre os valores gastos para a disposição final dos resíduos gerados nas Obras A e B, por bloco com 16 unidades habitacionais cada. Aqueles obtidos referentes ao comparativo de valores gastos para a disposição final dos resíduos gerados nas Obras A e B são mostrados na figura 6

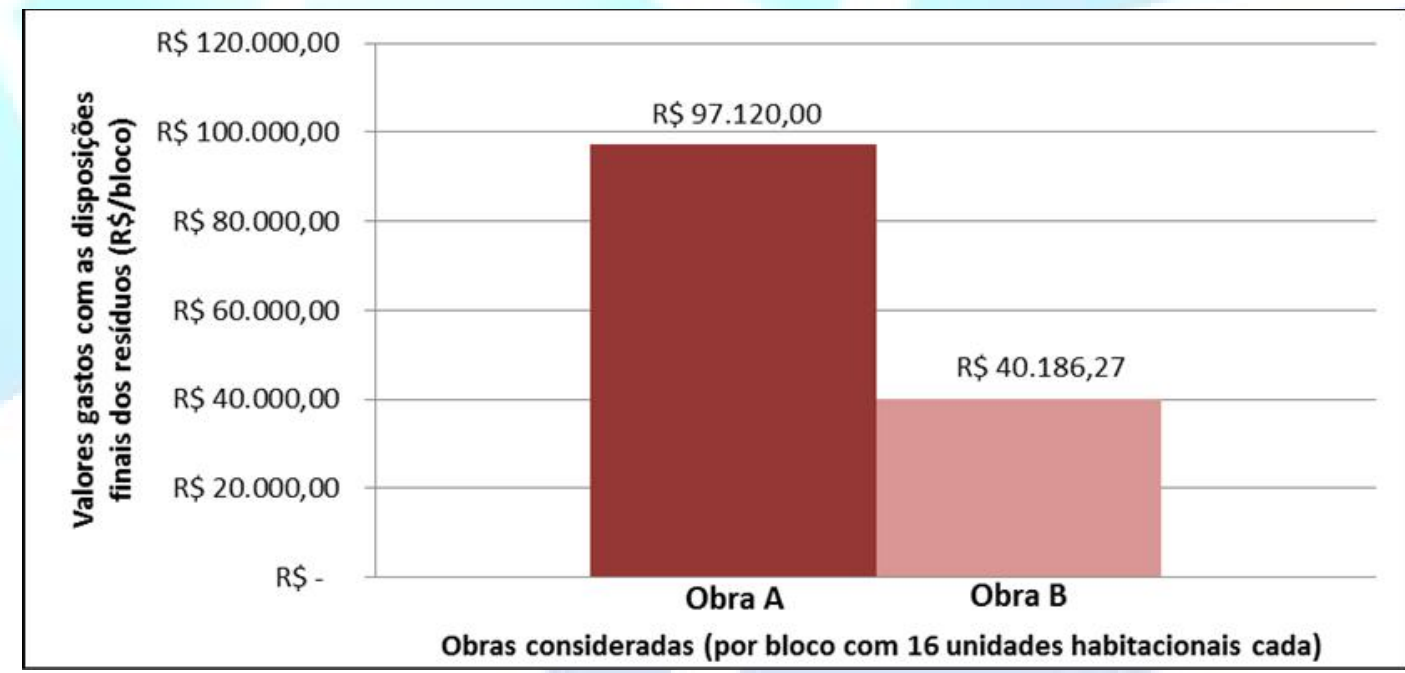

Figura 5. Comparativo de custos para a disposição final dos resíduos gerados $\left(\mathrm{m}^{3}\right)$, por bloco com 16 unidades habitacionais cada. Fonte: O próprio autor. 


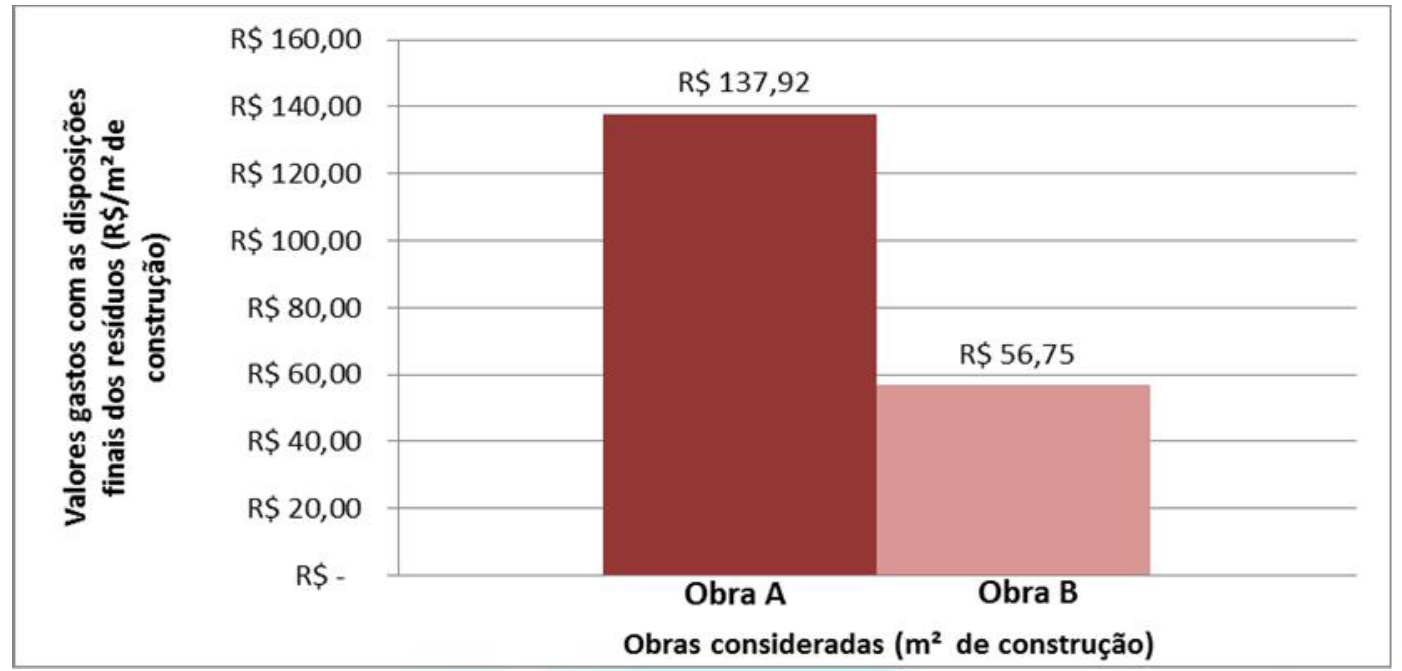

Figura 6. Comparativo de custos para a disposição final dos resíduos gerados $\left(\mathrm{m}^{3}\right)$, por $\mathrm{m}^{2}$ de construção.

Fonte: O próprio autor.

A figura 7 apresenta o impacto na Obra B, em porcentagem, entre o tempo utilizado para a implantação do plano e o tempo de execução da obra. Pode-se comprovar através de dados quantitativos a diminuição da geração de resíduos em uma obra com a implantação de PGRS. A partir dos dados apresentados nas tabelas 4 e 5 , e figura 4 , referentes ao volume gerado de resíduos por $\mathrm{m}^{2}$ de construção, constatou-se uma diminuição de $66,67 \%$ quando comparados os resultados da Obra A $\left(0,12 \mathrm{~m}^{3}\right.$ de resíduo/m² de construção) sem PGRS, com os resultados da Obra B, com PGRS $\left(0,04 \mathrm{~m}^{3} \mathrm{de}\right.$ resíduo $/ \mathrm{m}^{2}$ de construção $)$.

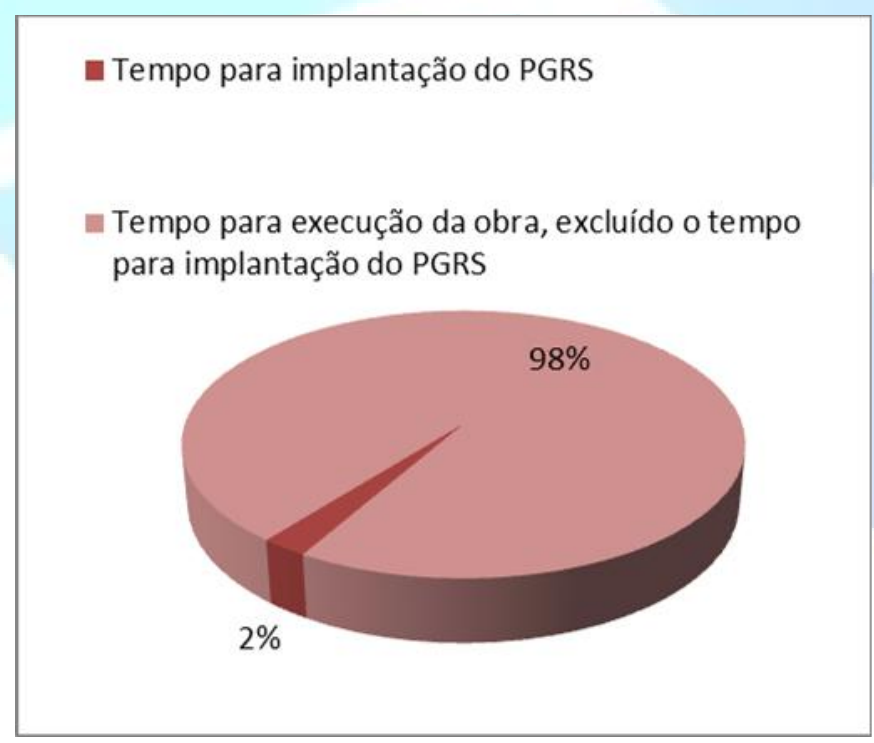

Figura 7. Percentual do tempo total da obra e o tempo utilizado para a implantação do PGRS. Fonte: O próprio autor. 
O tempo gasto para implantação de um plano de gerenciamento de resíduos, como visto na figura 7, mostrou-se bem reduzido, representando cerca de $2 \%$ do tempo total de execução, o que é de fundamental importância, uma vez que este plano foi aplicado desde o início do empreendimento. Dessa forma, todos os funcionários já iniciam seus trabalhos com as informações passadas durante a capacitação, conforme mostrado na figura $2 \mathrm{a}$, não permitindo que fossem adotados hábitos antigos que pudessem colocar em risco o bom andamento do trabalho.

Sendo assim, a principal resistência em aplicar o plano talvez seja em seu processo de implantação, que demanda de alguns dias de produção parada para capacitação dos funcionários. No entanto, como evidenciado nos resultados obtidos neste trabalho, estes dias considerados parados, sendo selecionados no início do empreendimento, mostraram-se pouco impactantes no cronograma geral. Esta capacitação também favorece o funcionamento do PGRS, pois reúne os funcionários que serão peças-chave para o sucesso do plano, e os informa desde o início sobre os procedimentos.

Os custos para a implantação do plano de gerenciamento de resíduos sólidos na Obra B, envolvendo custos para a execução e identificação das baias, adoção da coleta seletiva entre os funcionários, bem como a contratação de uma empresa especializada para criar o projeto, definir e explicar aos funcionários as ações do plano foram apresentados na tabela 4. Este custo inclui ainda os relatórios mensais emitidos por esta empresa após a implantação do plano, como forma de acompanhamento.

Quando são comparados os custos envolvidos com a disposição dos resíduos gerados nas Obras A e B, por $\mathrm{m}^{2}$ construído (Figura 6), observa-se que existe uma economia de $\mathrm{R} \$ 81,17 / \mathrm{m}^{2}$ construído já considerado o custo de implantação do PGRS. Este fato se torna bastante significativo quando são comparados os custos totais com a disposição final dos resíduos apresentados nas tabelas 5 e 6; sendo que mesmo com 77 blocos da Obra B contra 32 blocos da Obra A, o valor total gasto com os resíduos nas duas obras é praticamente o mesmo, o que demonstra uma economia de $58,62 \%$, na Obra B, com a disposição adequada dos resíduos.

Em relação aos custos totais das obras, verifica-se que o custo da destinação final dos resíduos na Obra $\mathrm{A}$, por $\mathrm{m}^{2}$ construído, representou $11,70 \%$ do custo total do $\mathrm{m}^{2}$ pronto do empreendimento. Enquanto que para a Obra B, esta destinação de resíduos representou, apenas, $4,98 \%$ do custo total da obra, uma redução de aproximadamente $7 \%$ no impacto causado pelo desperdício e perdas, ou seja, geração de resíduos sólidos que ocorre na obra.

É evidente a divergência dos valores e quantidades, embora sejam obras com áreas totais diferentes, mas de mesmo padrão executivo. Segundo dados da CAIXA (2013), pelo programa "Minha Casa Minha Vida", de março de 2009 (início do programa) até junho de 2013 foram entregues 1.247.859 unidades habitacionais similares às Obras A e B, objeto deste estudo. Com base neste valor estima-se que sejam construídas 24.467 unidades habitacionais/mês, em média. A partir dessa média e dos resultados encontrados neste trabalho, constata-se que se em todas as obras houvesse uma redução na geração de resíduos sólidos semelhante à ocorrida na Obra $\mathrm{B}$, de 0,08 $\mathrm{m}^{3} / \mathrm{m}^{2}$ construídos quando comparadas a Obra A, e que todas as obras tivessem o mesmo padrão da construtora analisada (unidades com aproximadamente $45 \mathrm{~m}^{2}$ ) deixariam de ser gerados aproximadamente $89.000 \mathrm{~m}^{3}$ de resíduos por mês, que seria uma contribuição significativa para a diminuição da geração e destinação inadequada de resíduos da construção civil.

\section{CONCLUSÕES}

Com base na metodologia aplicada e resultados obtidos, conclui-se que:

a implantação do Plano de Gerenciamento de Resíduos Sólidos contribui para a organização da obra, melhorando de forma significativa o ambiente de trabalho e as condições gerais de segurança; 
existe diminuição na geração de resíduos sólidos em obras que adotam o PGRS, que para os empreendimentos considerados neste estudo atingiu uma redução de $66,67 \%$, quando comparados os valores $\mathrm{em} \mathrm{m}^{3}$ de resíduos $/ \mathrm{m}^{2}$ de construção da obra; os custos envolvidos na destinação final dos resíduos foram reduzidos em $58,62 \%$ quando comparados os valores por $\mathrm{m}^{2}$ construído em obras com e sem PGRS, o impacto no tempo de execução total da obra devido à implantação do PGRS não foi significativo, atingindo um valor de aproximadamente $2 \%$, o impacto causado pela geração de resíduos sólidos no custo total da obra teve uma redução de aproximadamente 7\%.

\section{AGRADECIMENTOS}

Os autores agradecem à Construtora pelo fornecimento dos dados que possibilitaram a realização deste trabalho.

\section{REFERÊNCIAS}

BRASIL, 2002. Resolução no 307 - Conselho Nacional de Meio Ambiente (CONAMA). Publicada no DOU nº 136, em 17/07/2002, pags 95-96.

BRASIL, 2010. Lei 12.305 - Política Nacional de Resíduos Sólidos. Publicada no Diário Oficial da União $n^{\circ}$ 147, em03/08/2010, seção I, pag. 3.

BRASIL, 2011. Resolução no 431 - Conselho Nacional de Meio Ambiente (CONAMA). Publicada no Diário Oficial da União nº 99, em 25/05/2011, pag. 123.

BRASIL, 2012. Resolução no 448 - Conselho Nacional de Meio Ambiente (CONAMA). Publicada no DOU n ${ }^{\circ}$, em 19/01/2012. pag. 76.

CAIXA ECONÔMICA FEDERAL, 2013. NÚMEROS. Disponível em: $<$ http://mcmv.caixa.gov.br/numeros/>. Acesso em 07/09/2013.

CUNHA JÚNIOR, Nelson Boechat. Cartilha de gerenciamento de resíduos sólidos para a construção civil. SINDUSCON-MG, 2005. 38p..

PINTO, Tarcisio de Paula; GONZÁLEZ, Juan Luis Rodrigo. Guia profissional para uma gestão correta dos resíduos da construção - CREA-SP (Conselho Regional de Engenharia, Arquitetura e Agronomia do Estado de São Paulo), 2005. 44p..

SALGOSA, Ademar; DEL BEL, Diógenes. A importância da infraestrutura de destinação de resíduos sólidos. Revista SANEAS. São Paulo, 2012. Ano XII - nº 43. pags 17-19.

SiAC-Sistema de Avaliação da Conformidade de Empresas de Serviços e Obras da Construção Civil. Brasília, dezembro de 2012. 14p.. 